\title{
Do thick leaves avoid thermal damage in critically low wind
} speeds?

\author{
A. Leigh , S. Sevanto , M. C. Ball , J. D. Close , D. S. Ellsworth , C. A. Knight , A. B. Nicotra and S. Vogel
}

\begin{abstract}
Summary
- Transient lulls in air movement are rarely measured, but can cause leaf temperature to rise rapidly to critical levels. The high heat capacity of thick leaves can damp this rapid change in temperature. However, little is known about the extent to which increased leaf thickness can reduce thermal damage, or how thick leaves would need to be to have biological significance. We evaluated quantitatively the contribution of small increases in leaf thickness to the reduction in thermal damage during critically low wind speeds under desert conditions.

- We employed a numerical model to investigate the effect of thickness relative to transpiration, absorptance and leaf size on damage avoidance. We used measured traits and thermotolerance thresholds of real leaves to calculate the leaf temperature response to naturally occurring variable low wind speed.

- Our results demonstrated that an increase in thickness of only fractions of a millimetre can prevent excursions to damaging high temperatures. This damping effect of increased thickness was greatest when other means of reducing leaf temperature (transpiration, reflectance or reduced size) were lacking.

- For perennial desert flora, we propose that increased leaf thickness is important in decreasing the incidence of extreme heat stress and, in some species, in enhancing long-term survival.
\end{abstract}

\section{Introduction}

Extreme events, rather than long-term averages, are key determinants of biological adaptation and speciation (Gaines \& Denny, 1993; Venditti et al., 2010). Extreme temperature can be a major physiological stressor, particularly for plants, which are not motile. Extreme temperature events occur at different time scales. A heatwave could be considered as a macro-scale event, lasting several days. However, micro-scale extreme events of the order of minutes or seconds also occur; for example, during sun flecks underneath a plant canopy (Leakey et al., 2005) or with sudden drops in wind speed (Vogel, 2005). The contribution of very low wind speed as a source of acute heat stress is often overlooked. Meterological systems focus on averages over periods of minutes or hours, and on wind speeds $>0.5 \mathrm{~m} \mathrm{~s}^{-1}$. For much of the time, wind speeds as low as $0.5-1.0 \mathrm{~m} \mathrm{~s}^{-1}$ are sufficient to maintain air flow around leaves and to prevent excessive heating (Gates, 1962; Grace \& Wilson, 1976; Grace et al., 1980; Roden \& Pearcy, 1993). Yet, wind speeds below $0.5 \mathrm{~m} \mathrm{~s}^{-1}$ frequently occur in nature (Grace, 1977; Vogel, 2009), and even transient lulls can cause leaf temperature to rise by $>5^{\circ} \mathrm{C}$ in just a few seconds (Vogel, 2005). In desert environments, in which perennial plants are exposed to prolonged high irradiance and high temperatures, such a micro-scale wind lull could result in critically high leaf temperatures. Very little is known about the effects of fine-scale changes in air movement on leaf thermal damage, or which morphological features of leaves are likely to reduce the incidence of such damage.

To avoid rapid excursions to critically high temperatures during lulls in air movement, an optimally designed leaf should have a slower heating response time (longer time constant) than that of the drop in air movement driving the temperature increase. One way of achieving a longer time constant is to increase the thermal mass through increased thickness. An example is the large cladodes of American desert cacti, which can have time constants of several hours because of their great thermal mass (Nobel, 1988). More subtle changes in the thermal mass of much smaller plant parts, for example through increases in leaf thickness 
towards the outer canopy (Terashima et al., 2001; Panditharathna et al., 2008; Liang et al., 2010), may also play a role in thermal tolerance. In one of the few studies investigating this concept, Ball et al. (1988) showed that the large heat capacities of thick mangrove leaves at the top of a plant crown damp fluctuations in leaf temperature relative to thinner leaves, thereby reducing excursions into the temperature range unfavourable for photosynthesis. We might therefore expect that thick-leaved species in extreme temperature environments, such as deserts, have a similar advantage.

Because thick leaves frequently also have high leaf dry mass per area (LMA), a trait associated with an economic tradeoff in low-nutrient soils (Reich et al., 1997; Aerts \& Chapin, 2000; Westoby et al., 2002; Wright et al., 2002), the adaptive value of leaf thickness independent of LMA is seldom considered. Yet, within and across hundreds of species and biomes globally, thick leaves grow in high-temperature environments (James \& Bell, 1995; Niinemets, 2001; Vendramini et al., 2002; Wright \& Westoby, 2002; Voronin et al., 2003; Su et al., 2009). For example, succulent species in shrublands of Argentina have leaves exceeding $2 \mathrm{~mm}$ in thickness (Vendramini et al., 2002) and, in South African deserts, leaf thickness can reach $20 \mathrm{~mm}$ (von Willert et al., 1992). Even among nonsucculent flora, leaves tend to be thick in hot, dry environments. For example, scleromorphic leaves in semi-arid Australia can be $>1.0 \mathrm{~mm}$, almost an order of magnitude thicker than leaves in mesic regions, which often are $<0.2 \mathrm{~mm}$ (Roderick et al., 2000; Wright \& Westoby, 2002). The predominance of thick leaves in desert and semi-arid environments suggests that they may have adaptive benefit in reducing high-temperature stress. Rare evidence from Western Australia following an extreme heatwave event has indicated that thick-leaved species may better withstand thermal damage than species with thinner leaves (Groom et al., 2004). Although not measured, the authors suggested that the greater heat storage properties of thicker leaves are involved. However, other intrinsic attributes, such as leaf size and physiological heat tolerance, could influence the degree of damage (Groom et al., 2004). Thus, what remains unknown is the extent to which increased leaf thickness, relative to other leaf properties, can mitigate thermal damage.

In addition to thermal mass, leaf time constants for heating or cooling depend on the depth of the boundary layer, which is strongly influenced by leaf size (two-dimensional area; Monteith \& Unsworth, 1990; Schuepp, 1993). The effects of leaf size, leaf thickness and wind speed interact. Also, the relative influence of these factors on leaf temperature will vary depending on the spectral properties of the leaf; highly reflective desert leaves, for example, with an absorptance of visible light of 0.5 or lower, can greatly reduce incident heat load (Ehleringer et al., 1981). Latent heat loss through transpiration also reduces leaf temperature, although cooling can be negligible if hot, dry conditions cause stomatal closure (Barradas et al., 1994; Hamerlynck et al., 2000; Medeiros \& Pockman, 2010), which can result in leaf temperatures $15^{\circ} \mathrm{C}$ above ambient (Sharkey, 2005).

Together with these varying influences on leaf temperature, each species in a given environment possesses a certain thermal tolerance threshold, above which damage to photosynthetic machinery occurs. The role of increased leaf thickness in reducing the extent of excursions to a known damage threshold has never been investigated. Further, it is not known whether minor changes in leaf thickness could be sufficient to buffer against thermal damage relative to the strong influence of other leaf traits on leaf temperature.

We developed a model to determine the explicit role of leaf thickness, relative to transpiration, leaf size and leaf absorptance, in mitigating potential heat damage through the damping of temperature excursions to a known damage threshold. A further aim was to examine the extent to which changes in leaf water content affect the leaf temperature response. Lastly, given that some desert leaves are only moderately thick, we addressed whether minor changes in leaf thickness of $<1 \mathrm{~mm}$ would be sufficient to reduce thermal damage.

\section{Materials and Methods}

\section{Model description}

The leaf temperature model was based on the leaf energy balance equation (e.g. see Nobel, 2005):

$l_{\text {eaf }} C_{\text {leaf }} \frac{\mathrm{d} T_{\text {leaf }}}{\mathrm{d} t}=Q_{\text {in }}+\alpha\left(T_{\text {air }}-T_{\text {leaf }}\right)-\mathrm{LE}$ Eqn 1

where the rate of change in leaf temperature $\frac{\mathrm{d} T_{\text {leaf }}}{\mathrm{d} t}$ is determined by the balance between the radiative energy flux $\left(Q_{\mathrm{in}}\left(\mathrm{W} \mathrm{m}^{-2}\right)\right)$, the convective energy flux $\alpha\left(T_{\text {air }}-T_{\text {leaf }}\right)$ and the evaporative energy flux $L E . \alpha\left(\mathrm{W} \mathrm{m}{ }^{-2} \mathrm{~K}^{-1}\right)$ is the convective heat transfer coefficient; $T_{\text {air }}$, ambient temperature; $L\left(\mathrm{~J} \mathrm{~kg}^{-1}\right)$, latent heat for evaporation of water; $E\left(\mathrm{~kg} \mathrm{~m}^{-2} \mathrm{~s}^{-1}\right)$, transpiration rate; leaf, leaf thickness; $C_{\text {leaf }}\left(\mathrm{J} \mathrm{m}^{-3} \mathrm{~K}^{-1}\right)$, specific thermal capacity of the leaf.

The radiative heat flux $\left(Q_{\text {in }}\right)$ consists of the direct, reflected and diffuse solar radiation absorbed by the leaf at visible wavelengths, the infrared (IR) radiation absorbed by the leaf and the IR radiation emitted by the leaf. The IR radiation absorbed by the leaf further consists of the IR radiation emitted by the atmosphere and the surroundings. This radiative heat flux term is written as:

$$
\begin{array}{r}
Q_{\text {in }}=a_{\text {short }}(1+r)\left(S_{\text {direct }}+S_{\text {diffuse }}\right)+a_{\mathrm{IR}} \sigma\left(T_{\text {sky }}^{4}+T_{\text {surf }}^{4}\right)-2 e_{\mathrm{IR}} T_{\text {leaf }}^{4} \\
\text { Eqn } 2
\end{array}
$$

where $S\left(\mathrm{~W} \mathrm{~m}^{-2}\right)$ is the solar radiation at visible wavelengths; $a_{\text {short }}$ and $a_{\mathrm{IR}}$ are the leaf absorptance at visible and IR wavelengths, respectively; $e_{\mathrm{IR}}$, leaf emissivity at IR wavelengths; $\sigma$, Stefan-Boltzman constant $\left(5.67 \times 10^{-8} \mathrm{~W} \mathrm{~m}^{-2} \mathrm{~K}^{-4}\right) ; T_{\text {sky }}$ and

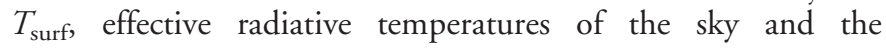
surroundings, respectively (Gates, 1968; Nobel, 2005). The multiplier ' 2 ' in the last term accounts for the radiation being emitted from both leaf surfaces. We assumed that the leaf was some distance from the ground and, consequently, the leaf area for forced convection took both upper and lower surfaces into account. Solar direct radiation was incident only on the top surface, as was 
the radiation from the sky. Reflected solar radiation from the surroundings and IR radiation from the surfaces were incident upon the lower surface only.

For convective cooling, we calculated the heat transfer coefficient $(\alpha)$ on the basis of the relationship between the Nusselt number $(N u)$ and Reynolds number $(R e)$ determined for a circular horizontal disc of the diameter of the leaf (see, for example, Monteith \& Unsworth, 1990; Bird et al., 2002):

$\alpha=N u \frac{k}{d}$

Eqn 3

where $k\left(0.026 \mathrm{~W} \mathrm{~m}^{-1} \mathrm{~K}^{-1}\right.$ is the thermal conductivity of air; $d$, the diameter of the leaf. The diameter of the leaf was defined as the diameter of the largest circle that could be inscribed within the leaf margins. This measure provides the largest continuous width across a leaf from the windward edge, whilst also accounting for leaves of different shapes, for which a single width calculation is otherwise complicated (Schuepp, 1993). Following Monteith \& Unsworth (1990) and Bird et al. (2002), the equations used to calculate the Nusselt number for laminar and turbulent forced convection were:

$N u=0.60 R e^{0.5}$

Eqn 4

$N u=0.032 R^{0.8}$

To account for a potentially more efficient heat transfer by convection from real leaves than from a circular disc (Schuepp, 1972; Grace \& Wilson, 1976; Nobel, 2005), we selected a Reynolds number $(R e)$ for transition to turbulent flow at the lower end of the range given for flat plates, namely $1 \times 10^{4}$ (Bird et al., 2002).

At very low wind speeds, the majority of convective cooling occurs via free or mixed convection (a combination of forced and free convection), rather than forced convection alone (Bird et al., 2002). To take this into account, we calculated the Grashof number $(G r)$ as:

$G r=\frac{g \rho^{2} \beta \Delta \mathrm{Td}^{3}}{\mu^{2}}$

Eqn 6

where $g\left(9.81 \mathrm{~m} \mathrm{~s}^{-2}\right)$ is the gravitational acceleration; $\rho$, the density of air; $\beta$, the volumetric thermal expansion coefficient of air; $\Delta T$, the temperature difference between ambient air and the leaf; $d$, the leaf diameter; $\mu$, the viscosity of air. The Grashof number describes the relative importance of buoyancy forces relative to viscous forces in the flow, and the relative magnitudes of $G r$ and $R e$ can be used as an indicator of the relative importance of free and forced convection in cooling an object (Bird et al., 2002). Here, when $G r$ was $<10$ times larger than $R e^{2}$, we used the equations for forced convection (laminar or turbulent, depending on $R e$ ). If $G r R e^{-2}>0.1$, we replaced $\alpha$ from Eqn 1 with the heat transfer coefficient for mixed convection using the scheme presented in Bird et al. (2002): $\alpha_{\text {mixed }}=\left(N u_{\text {forced }}{ }^{1 / 3}+N u_{\text {free }}{ }^{1 / 3}\right)^{3} \frac{k}{d}$

where the equation for free convection determined for real leaves by Dixon \& Grace (1983) is:

$N u_{\text {free }}=2.67 G r^{0.122}$

Eqn 8

and $N u_{\text {forced }}$ is calculated using Eqn 4. At low wind speeds, free convection thus enhances heat transfer relative to pure forced convection. If wind speed vanishes completely, Eqn 7 results in a heat transfer coefficient of pure free convection.

The model was written using Matlab 7.7 (The MathWorks Inc., Natick, MA, USA). In the model, Eqn 1 was solved numerically using the Runge-Kutta four method and a time step of $0.093 \mathrm{~s}$. The driver of leaf temperature fluctuations was a predescribed wind speed regime (adapted from Vogel, 2005, described later in this paragraph). At each time step, the heat transfer coefficient (Eqn 3) was determined using the appropriate equation (Eqn 4, 5 or 7), depending on the wind speed and the temperature difference between the leaf and ambient air at the previous time step. The incoming solar radiation (both direct and diffuse), ambient temperature and the effective temperature of the sky and the surroundings were set constant and made to represent clear sky conditions on a summer's day in a desert (see Table 1). The heat capacity for each species was calculated as the mass fractionweighted average based on the measured water content and dry density of each leaf (see Measured leaf traits, below). The heat capacity for dry matter was set at $1.3 \mathrm{MJ} \mathrm{m}^{-3} \mathrm{~K}^{-1}$ (Simpson \& TenWolde, 1999; Jayalakshmy \& Philip, 2010). The short-term variation in the wind speed was reconstructed from the 9-min wind speed regime measured by Vogel (2005) using a heated thermistor at the top of an oak canopy. This wind regime is comparable with the wind speed regimes recorded around Australian desert shrubs during a hot summer's day (A. Leigh and N. Booth, unpublished data). The leaf temperature was initially set to ambient and the model was run for several consecutive 9-min wind speed cycles. The model always equilibrated during the first 9-min cycle. Leaves of the same diameter, irrespective of thickness, equilibrated at the same average temperature, with large leaves equilibrating at higher temperatures than small leaves. For presentation and calculations, we omitted the first wind speed cycle to remove the effects of equilibration.

To validate the performance of our model, we conducted two different tests. First, we tested the accuracy of the numerical solution method against an analytical solution for Eqn 1; second, we tested the model with field measurements of real leaves of an arid zone species (details in Supporting Information Notes S1). The tests found the numerical solution to only slightly underestimate the amplitude of temperature variation relative to the analytical solution, and the model captured the amplitude and nuances of leaf temperature variation very well.

To tease apart the effects of leaf size, thickness and thermal mass on leaf temperature during lulls in wind speed, we wrote Eqn 1 for a situation in which a leaf is in radiative equilibrium (no transpiration) and the only driving force for leaf temperature 
Table 1 Model parameters, their values and sources, estimated for summertime desert conditions

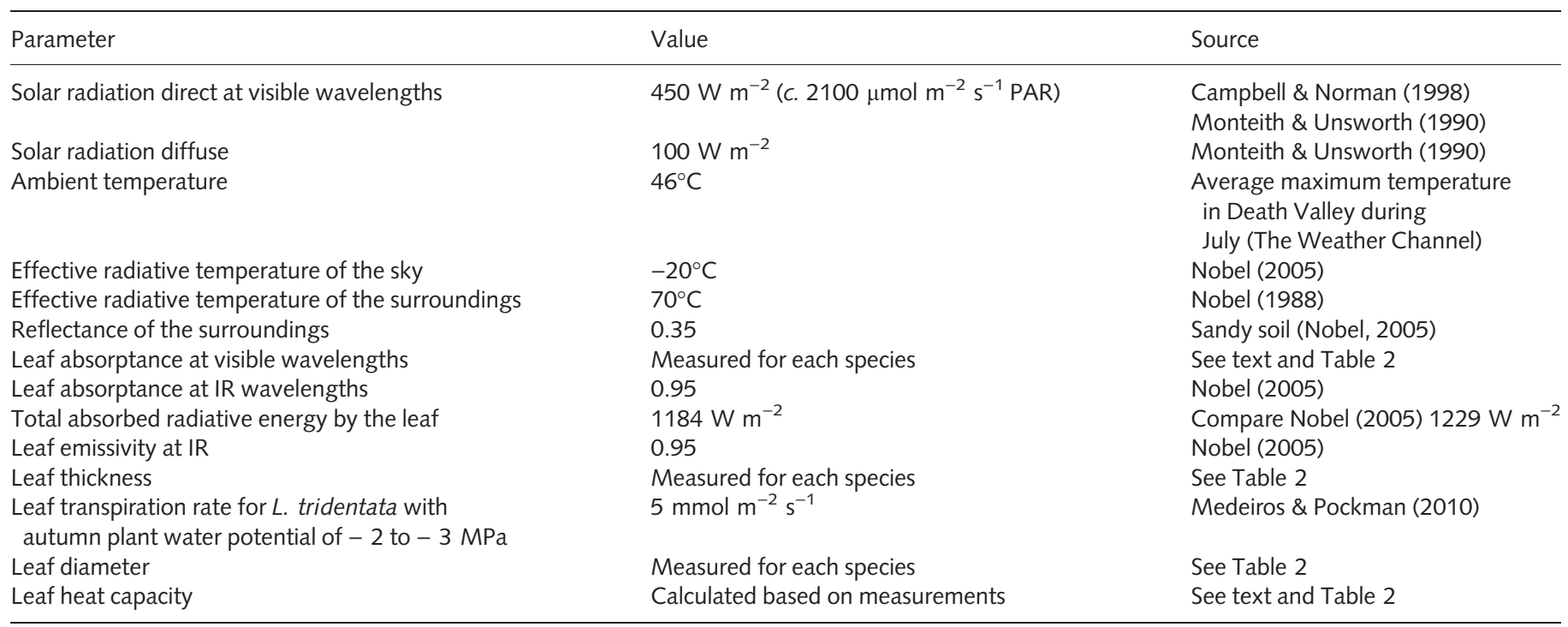

changes is convective heat transfer. Integrating this equation to obtain leaf temperature as a function of time results in an exponential function with a time constant $\tau$ that depends only on the leaf thickness $\left(l_{\text {leaf }}\right)$, specific thermal capacity of the leaf $\left(C_{\text {leaf }}\right.$ $\left.\left(\mathrm{J} \mathrm{m}^{-3} \mathrm{~K}^{-1}\right)\right)$ and the convective heat transfer coefficient $(\alpha$ (W $\left.\mathrm{m}^{-2} \mathrm{~K}^{-1}\right)$ ):

$\tau=\frac{l_{\text {eaf }} C_{\text {leaf }}}{\alpha}$

Eqn 9

The time constant is essentially the ratio of the leaf thermal mass (numerator) to the boundary layer conductance (denominator); it determines the speed with which the leaf temperature responds to a step change in ambient temperature (deviation from equilibrium) via convective cooling. The heat transfer coefficient $\alpha$, which represents the effects of the boundary layer on the time constant, depends on the leaf size (two-dimensional area) (see Eqns 3-8); the larger the leaf, the longer the time constant. By inserting Eqns 4 and 5 into the time constant, we can see that, for laminar forced convection, for example:

$\tau \propto l_{\text {leaf }} C_{\text {leaf }} \sqrt{\frac{d}{v}}$

Eqn 10

Here, $d$ denotes the leaf diameter and $v$ the wind speed. In the case of turbulent flow, the time constant depends more strongly on the wind speed than size (leaf diameter; $\tau \propto d^{0.2} v^{-0.8}$ ), whereas, under pure laminar free convection (Eqn 8), size dominates over the driving force for cooling, which becomes the temperature difference between ambient air and the leaf $\left(\tau \propto d^{0.634} \Delta T^{0.122}\right)$. It should be noted that the heat transfer coefficient, and therefore also the time constant, is not in fact a constant, but changes with changing wind speed or leaf-air temperature difference. It should also be noted that, in Eqns 9 and 10 , the specific thermal capacity does not change with leaf size.

\section{Measured leaf traits}

To maintain biological and ecological relevance, we used the leaf parameters of Californian desert species with previously measured thermal damage thresholds $T_{\mathrm{S} 20}$ (the temperature at which leaf baseline fluorescence reaches $20 \%$ of its maximum; Knight \& Ackerly, 2002): Atriplex hymenelytra, Encelia farinosa, Isocoma acradenia and Larrea tridentata. For these species, additional leaf properties were measured at the end of the growing season in 2009 (Table 2). Small branches were removed from 5-10 plants per species and placed in zip-lock plastic bags for the analysis of leaf area, thickness, water content, dry density and absorptance. For each species, 7-10 fully expanded leaves were removed from branches and allowed to fully hydrate in the bags with a wet sponge for at least $2 \mathrm{~h}$ before patting dry and weighing,

Table 2 Measured leaf properties for species with known $T_{\mathrm{S} 2 \mathrm{O}}$ thresholds previously collected from the Californian desert (Knight \& Ackerly, 2002)

\begin{tabular}{|c|c|c|c|c|c|c|}
\hline Species & $\begin{array}{l}\text { Thickness } \pm \\
\text { SD }(\mathrm{mm})\end{array}$ & $\begin{array}{l}\text { Leaf } \\
\text { diameter } \pm \text { SD }(\mathrm{mm})\end{array}$ & $\begin{array}{l}\text { Water } \\
\text { content } \pm S D\end{array}$ & 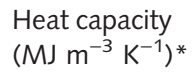 & $\begin{array}{l}\text { Mean absorptance } \\
\text { at visible wavelengths }\end{array}$ & $T_{\mathrm{S} 20}\left({ }^{\circ} \mathrm{C}\right)$ \\
\hline Atriplex hymenelytra & $0.6 \pm 0.08$ & $18 \pm 4$ & $0.48 \pm 0.04$ & 2.2 & 0.46 & 52.6 \\
\hline Encelia farinosa & $0.4 \pm 0.05$ & $36 \pm 4$ & $0.68 \pm 0.02$ & 3.0 & 0.52 & 49.8 \\
\hline Isocoma acradenia & $0.6 \pm 0.07$ & $6 \pm 1$ & $0.60 \pm 0.05$ & 2.6 & 0.78 & 49.9 \\
\hline Larrea tridentata & $0.4 \pm 0.06$ & $4 \pm 0.5$ & $0.59 \pm 0.07$ & 2.6 & 0.85 & 53.7 \\
\hline
\end{tabular}

* Heat capacity for each species was calculated as the mass fraction-weighted average based on the water content and the dry density of each leaf (see text). 
scanning for area and oven drying to constant mass for dry weight measurements. Water content was calculated as a percentage: (fresh weight - dry weight)/fresh weight; dry density was calculated as dry weight/volume (area $\times$ thickness) in $\mathrm{kg} \mathrm{m}^{-3}$. Leaf thickness was measured multiple times on 5-10 fresh leaves per species using a digital gauge (accurate to $0.01 \mathrm{~mm}$ ), with arched callipers of $1 \mathrm{~mm}$ in diameter placed midway along the leaf blade and avoiding major veins. Leaf reflectance was measured on the upper surface of fresh leaves with a SpectraWiz fibre optic spectroradiometer and configured SL1 Tungsten Halogen light source (StellarNet Inc., Tampa, Florida, USA) referenced to dark and light standards before measurements. Absorptance was calculated from the reflectance as the proportion of light not reflected from or transmitted through the leaf. For the purposes of this study, we assumed zero transmittance, as leaf transmittance represents a negligible proportion of incident light at visible wavelengths (Sinclair \& Thomas, 1970).

\section{Application of the model}

The investigation was carried out in two stages. First, we addressed whether relatively small differences in leaf thickness (up to $0.8 \mathrm{~mm}$ ) could have any notable influence on the damping of the amplitude of the leaf temperature response compared with the effects of leaf transpiration rate, absorptance, size and water content. Second, we determined whether increased leaf thickness, via an influence on the amplitude of the leaf temperature response, could prevent thermal damage for different desert species during a sudden drop in wind speed on a hot day under desert conditions (Table 1).

The first stage of the study used L. tridentata (Creosote Bush), a widespread species in the deserts of south-west USA and Mexico, to examine the effect of leaf thickness relative to transpiration (latent heat loss), absorptance (radiative load) and size (boundary layer) by simulating changes in each parameter. To estimate the effects of latent heat loss when soil and plant water potential are relatively favourable, we used a transpiration rate of $5 \mathrm{mmol} \mathrm{m}^{-2} \mathrm{~s}^{-1}$, appropriate for L. tridentata in late autumn (October) (Medeiros $\&$ Pockman, 2010). Because the water vapour concentration gradient from stomata to air outside a leaf increases with increasing leaf temperature, a drop in wind speed could lead to an increase in transpirational cooling. However, the extent of this effect, particularly for leaves close to ambient temperature under hot summer conditions, is slight, that is, a change in leaf temperature of $<0.05^{\circ} \mathrm{C}$ (Notes S2, Fig. S1). Therefore, in this experiment, the imposed transpiration rate was set to be constant. Absorptance was made to vary from the normal (measured) absorptance for L. tridentata of 0.8 to a hypothetical reflective counterpart with an absorptance of 0.3 . Leaf size was made to vary from the normal (measured) L. tridentata diameter of $4 \mathrm{~mm}$ to a hypothetical large leaf, similar to a comparatively large-leaved American desert species, E. farinosa, at $40 \mathrm{~mm}$. Leaf thickness was set to $1.0 \mathrm{~mm}$, representing a moderately thick leaf, typical of many nonsucculent arid zone species (Wright \& Westoby, 2002), with a hypothetical thin leaf set at $0.2 \mathrm{~mm}$, representing more temperate species (Roderick et al., 2000; Wright \& Westoby, 2002). In addition, given the high thermal mass of water, we examined the effect of changing water content, relative to the influence of transpiration, absorptance and size, whilst holding the thickness constant. For each case, we calculated the results for an $L$. tridentata leaf of high (0.85), normal (0.59) and low (0.35) water content.

In the second stage of the study, we used the model to examine the relative effects of thickness on the buffering against excursions to damaging leaf temperatures in Californian desert species with known damage thresholds $\left(T_{\mathrm{S} 20}\right)$ (Knight \& Ackerly, 2002). As well as varying in thermal tolerance, these species also vary morphologically, especially in absorptive properties (Table 2). The environmental conditions were set to represent a hot summer's day in the Mojave Desert: an ambient temperature of $46^{\circ} \mathrm{C}$ and a soil surface temperature of $70^{\circ} \mathrm{C}$ (Table 1). During southern American desert conditions in late summer, particularly when soil and plant water potentials become critically low, stomatal conductance in $L$. tridentata ceases altogether (Hamerlynck et al., 2000; Medeiros \& Pockman, 2010). Under such conditions, leaves are particularly vulnerable to thermal damage; thus, the second part of the study assumed an absence of transpirational cooling. Here, we looked at the effect of thickness by first simulating the leaf temperature response to the wind speed regime for a leaf of normal (measured) thickness for each species (Table 2), and then reducing the thickness to a 'thin' $0.2 \mathrm{~mm}$.

\section{Results}

\section{Effects of different parameters on the leaf temperature response}

A modelled $L$. tridentata leaf transpiring at $5 \mathrm{mmol} \mathrm{m}^{-2} \mathrm{~s}^{-1}$ maintained a lower average temperature $\left(46.8^{\circ} \mathrm{C}\right)$ and smaller amplitude of the temperature response $\left(0.8^{\circ} \mathrm{C}\right)$ than a nontranspiring leaf (Fig. 1). A modelled large leaf ( $40 \mathrm{~mm}$ across) reached a higher average temperature $\left(50.4^{\circ} \mathrm{C}\right)$ than a small leaf $(4 \mathrm{~mm})$ because of its low convective heat transfer coefficient (i.e. deep boundary layer; Eqns 1-8). Because the convective heat transfer rate is proportional to the temperature difference between leaf and air (Eqn 1), an elevated average leaf temperature affected the amplitude of the leaf temperature fluctuations. If a wind speed lull was of sufficient duration (1 min, e.g. from Time 3-4 in Fig. 1), the overall amplitude of the leaf temperature response of the larger leaf was greater than that of the small leaf. However, during more rapid fluctuations in air movement (a few seconds, Time 4 in Fig. 1), the time constant of the larger leaf was large enough to damp rapid leaf temperature fluctuations relative to small leaves (Eqns 9, 10) (Fig. 1). Conversely, an increase in leaf reflectance (or reduction in absorptance from 0.8 to 0.3 ) reduced the average leaf temperature by over $1.3^{\circ} \mathrm{C}$ and the amplitude by $1.7^{\circ} \mathrm{C}$ (Fig. 1). This strong amplitude damping effect of greater reflectance was caused by a lower energy load, creating a lower average leaf temperature and a smaller leaf-air temperature difference, which, in turn, reduced the amplitude of the leaf temperature response.

In contrast with the above parameters, a change in leaf thickness had a negligible effect on the average leaf temperature, but had a considerable damping effect on the amplitude of the 

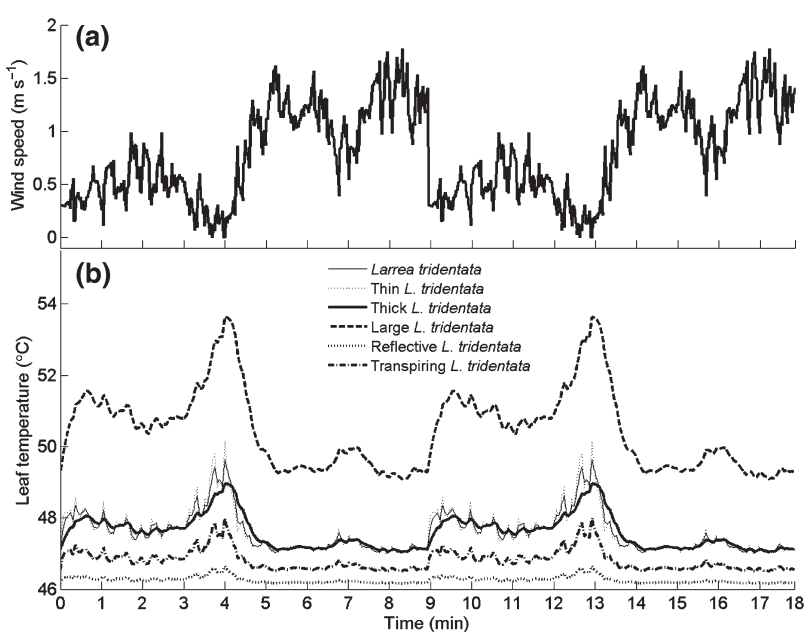

Fig. 1 Modelled leaf temperature response to varying wind speed (a) of a normal Larrea tridentata leaf (thin solid line; b), hypothetical thin L. tridentata leaf (thin dotted line; b), hypothetical thick leaf (thick solid line; b), hypothetical large leaf (thick dashed line; b), hypothetical highly reflective leaf (thick dotted line; b) and a transpiring leaf (thick dasheddotted line; b). The wind speed regime was digitized from the measured wind speed of Vogel (2005, see text) and run for two cycles. The thickness of the normal leaf was $0.4 \mathrm{~mm}$, the size was $4 \mathrm{~mm}$ (diameter), the absorptance was 0.8 and the relative water content was 0.6 (heat capacity, $2.6 \mathrm{MJ} \mathrm{m}^{-3} \mathrm{~K}^{-1}$ ). The thickness of the thin leaf was $0.2 \mathrm{~mm}$, the size of the large leaf was $40 \mathrm{~mm}$, the absorptance of the highly reflective leaf was 0.3 and the transpiration rate of the transpiring leaf was $5 \mathrm{mmol} \mathrm{m}^{-2} \mathrm{~s}^{-1}$. In each case, all other leaf and environmental parameters were held constant, that is, set to represent summertime desert conditions (see Table 1).

temperature response to sudden lulls in air movement (Fig. 1). The L. tridentata leaf of normal thickness $(0.4 \mathrm{~mm})$, together with its hypothetical thin $(0.2 \mathrm{~mm})$ and thick $(1.0 \mathrm{~mm})$ counterparts, averaged $47.6^{\circ} \mathrm{C}$. However, during critical wind speed lulls, the modelled thin leaf achieved peak temperatures up to $0.4^{\circ} \mathrm{C}$ higher than those of the modelled normal leaf, and $1.2^{\circ} \mathrm{C}$ higher than those of the modelled thick leaf.

\section{Overall and relative damping effects of different leaf traits}

Next, we sought to tease apart the effect of leaf thickness relative to the effects of other traits on the leaf temperature response. This step involved the calculation of the differences between the peak temperatures reached during the wind speed cycles of two leaves varying in a given parameter, whilst keeping the other parameters constant (Fig. 2). We define this difference in peak temperatures as the 'damping effect' on the amplitude of the temperature response resulting from a change in a given leaf property. For example, the difference in peak temperature obtained by changing the absorptance from high to low is defined here as the damping effect of reducing absorptance. We recognized that transpiration, absorptance and size influence both the average leaf temperature and the amplitude of the temperature response (see Fig. 1). Therefore, we compared the overall damping effect of the change in each of these parameters by considering absolute maximum leaf temperatures, and the relative damping effect after adjusting the mean temperature of the leaves of different values for a parameter (e.g. large and small leaves) to be equal. The latter comparison gives the damping effect of the change in a given parameter only on the amplitude of the temperature response. For calculations of the damping effect of increasing thickness at different transpiration rates, absorptances and sizes, the distinction between overall and relative damping was not necessary because changing thickness did not alter the average leaf temperature, only the amplitude of the response (see Fig. 1).

\section{Damping effect of transpiration vs increased thickness}

The damping effect of increasing transpiration rate from 0 to $5 \mathrm{mmol} \mathrm{m} \mathrm{s}^{-2} \mathrm{~s}^{-1}$ decreased in a curvilinear fashion as a function of leaf thickness (Fig. 2a). The damping effect of increasing thickness from 0.2 to $1.0 \mathrm{~mm}$ decreased linearly with increasing transpiration rate (Fig. 2b). The overall temperature damping effect of transpiration was greater than the damping effect of increasing thickness, whereas the relative damping effect of transpiration was similar to that achieved by increasing thickness (Fig. 2). For modelled leaves transpiring at $10 \mathrm{mmol} \mathrm{m}^{-2} \mathrm{~s}^{-1}$, a rate possible for young, rapidly growing $L$. tridentata plants in optimal conditions (Medeiros \& Pockman, 2010), increasing thickness did not damp peak temperatures (Fig. 2b). However, for a transpiration rate of $5 \mathrm{mmol} \mathrm{m} \mathrm{m}^{-2}$, typical of established plants under favourable conditions, increasing thickness achieved a damping effect of $c \cdot 0.5-0.7^{\circ} \mathrm{C}$, depending on the leaf water content. In other words, during a wind lull on a hot day, a thin leaf transpiring at $5 \mathrm{mmol} \mathrm{m} \mathrm{m}^{-2}$ would achieve a peak temperature at least $0.5^{\circ} \mathrm{C}$ higher than a thick leaf. For nontranspiring L. tridentata leaves under hot, dry summer conditions, the damping effect of increasing thickness was as high as $1.0^{\circ} \mathrm{C}$ (Fig. 2b).

\section{Damping effect of reduced absorptance vs increased thickness}

The damping effect of reducing absorptance (from 0.8 to 0.3 ) decreased in a curvilinear fashion as a function of leaf thickness (Fig. 2c). The damping effect of increasing leaf thickness increased as a function of absorptance (Fig. 2d). For this range of realistic leaf thicknesses $(0.2-1.0 \mathrm{~mm})$, the relative and overall damping effects of reducing absorptance were always greater than the damping effect of increasing thickness. However, for very absorptive leaves $(\geq 0.8)$, the damping effect of increasing thickness to $1 \mathrm{~mm}$ was of the same order of magnitude as the relative damping effect of reducing absorptance to 0.3 .

\section{Damping effect of reduced size vs increased thickness}

The damping effect of reducing leaf size from 40 to $4 \mathrm{~mm}$ decreased as a function of leaf thickness (Fig. 2e). The damping effect of increasing thickness from 0.2 to $1.0 \mathrm{~mm}$ initially rose sharply with an increase in leaf size and then continued to increase more gradually (Fig. 2f). The absolute damping effect of reducing leaf size was always greater than the damping effect of increasing thickness to $1 \mathrm{~mm}$. However, for leaves $>40 \mathrm{~mm}$, the damping effect of increasing thickness to a modest $1 \mathrm{~mm}$ was greater than the relative damping effect of reducing leaf size to $4 \mathrm{~mm}$. 
Fig. 2 The leaf temperature damping effect resulting from the alteration of the transpiration rate, absorptance, size, thickness and water content of Larrea tridentata leaves. The damping effect is the difference in maximum temperatures reached by leaves obtained by changing a given parameter. The left-hand panel shows the damping effect of increasing the transpiration rate from zero to $5 \mathrm{mmol} \mathrm{m} \mathrm{m}^{-2} \mathrm{~s}^{-1}$ (a), reducing the absorptance from high $(0.8)$ to low (0.3) (c), and decreasing the size from large (40 $\mathrm{mm}$ in diameter) to small (4 $\mathrm{mm}$ in diameter) (e) as a function of leaf thickness. The right-hand panel shows the damping effect of increasing the thickness from thin $(0.2 \mathrm{~mm})$ to thick $(1 \mathrm{~mm})$ as a function of the transpiration rate (b), absorptance (d) and size ( $f$ ). Closed symbols represent leaves with a relative water content of a normal L. tridentata leaf (0.59); open circles represent low relative water content (0.35); open triangles represent high relative water content $(0.85)$. The relative damping effects in (a), (c) and (e) were calculated by first adjusting the mean temperatures of the leaves of high and low transpiration, absorptance and size to be equal, and calculating the difference between the maximum leaf temperatures resulting from a large drop in wind speed at 4 or 13 min (see Fig. 1)
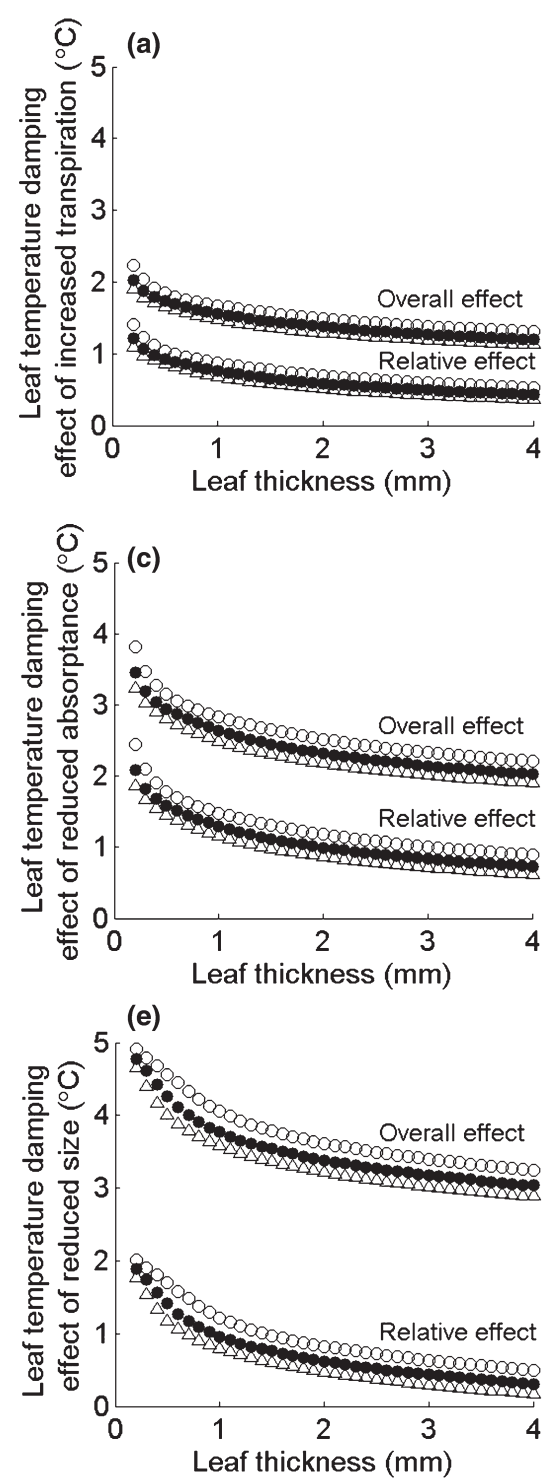
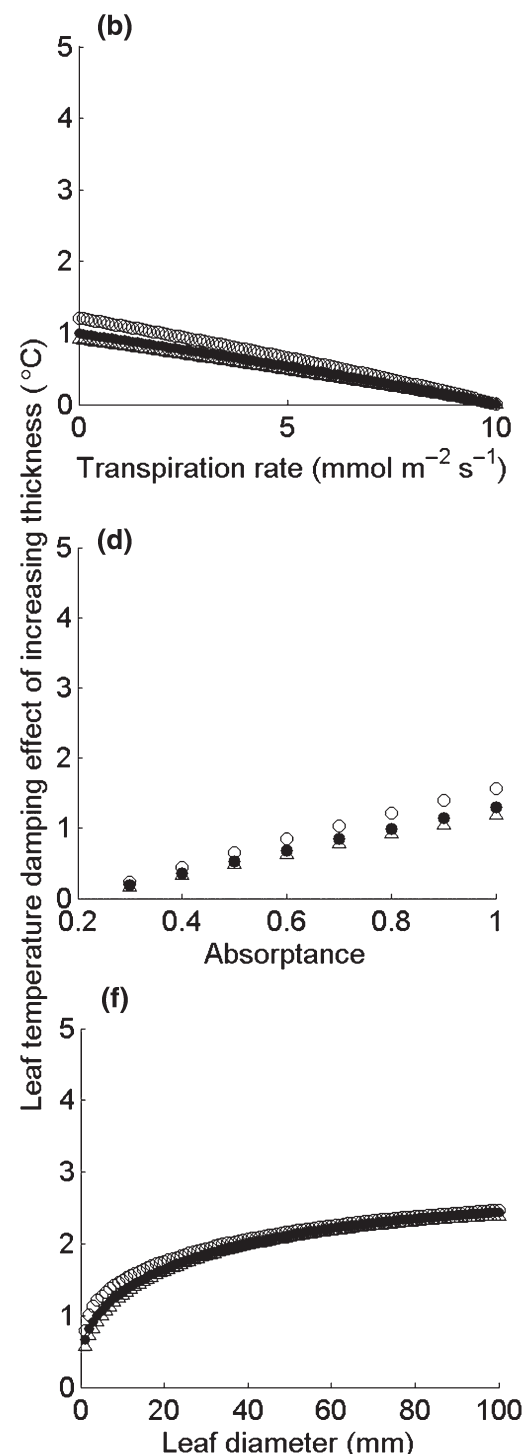

Unlike a change in absorptance or transpiration, a change in leaf thickness or size affects the time constant of a leaf (Eqns 9, 10). Therefore, the damping effect of reduced size or increased thickness depends on the duration and strength of a wind speed lull, as well as on the thresholds for transition between different types of convective cooling ( $R e$ and $G r R e^{-2}$; see the Materials and Methods section). We investigated the effects of changing the threshold for the transition from laminar to turbulent forced convection and from laminar forced convection to mixed convection, as well as the frequency of wind speed fluctuations (Notes S1). A change in these thresholds had a minor influence on the broad relationships between leaf size and thickness.

\section{Damping effect of increasing water content vs increased thickness}

To examine the damping effect resulting from increasing water content, we repeated each calculation varying only the leaf water content (Fig. 2a-f). Increasing water content relative to dry matter reduced slightly both the absolute and relative damping effects of increasing transpiration and decreasing absorptance or size (Fig. 2a,c,e). High water content also reduced slightly the damping effect of increasing thickness for small leaves $(<10 \mathrm{~mm}$ in diameter) and when transpiration was low or absorptance high (Fig. 2b,d,f). For leaves with high transpiration rates, low absorptance or large size, increasing water content had a negligible influence on the damping effect of increased thickness, whereas decreasing water content improved slightly the damping effect of increased thickness. In general, however, the changes in the damping effects produced by changing water content from 0.35 (very dry leaves) to 0.85 (succulent leaves) were small relative to changing any other parameter within a natural biological range.

\section{Effects of leaf thickness on leaf thermal damage}

Finally, we examined the extent to which increased thickness could reduce thermal damage in non-transpiring leaves of 
American desert species with known damage thresholds. In our simulation, the effect of thickness was dependent on a leafs absorptive properties and size, as well as on the damage threshold of a given species (Fig. 3). Low absorptance reduced both the average leaf temperatures and amplitude of the response of the more reflective $A$. hymenelytra and $E$. farinosa leaves, with absorptances of 0.46 and 0.52 , respectively (Fig. 3). For both of these species, leaf thickness damped rapid excursions (compare peaks for thick and thin leaves at Time 4), but the two species differed with respect to thermal damage. The relatively low average temperature of $A$. hymenelytra, $47.2^{\circ} \mathrm{C}$, coupled with its high thermal tolerance threshold of $52.6^{\circ} \mathrm{C}$, meant that this species easily avoided thermal damage under the modelled conditions. By contrast, as a result of being twice the size of $A$. hymenelytra leaves, the average temperature of modelled $E$. farinosa leaves was slightly higher, at $48.3^{\circ} \mathrm{C}$, such that they remained close to their lower damage threshold of $49.8^{\circ} \mathrm{C}$. Here, a lull in air movement caused the temperature of the hypothetical thin E. farinosa leaf to exceed the damage threshold twice during one wind cycle,

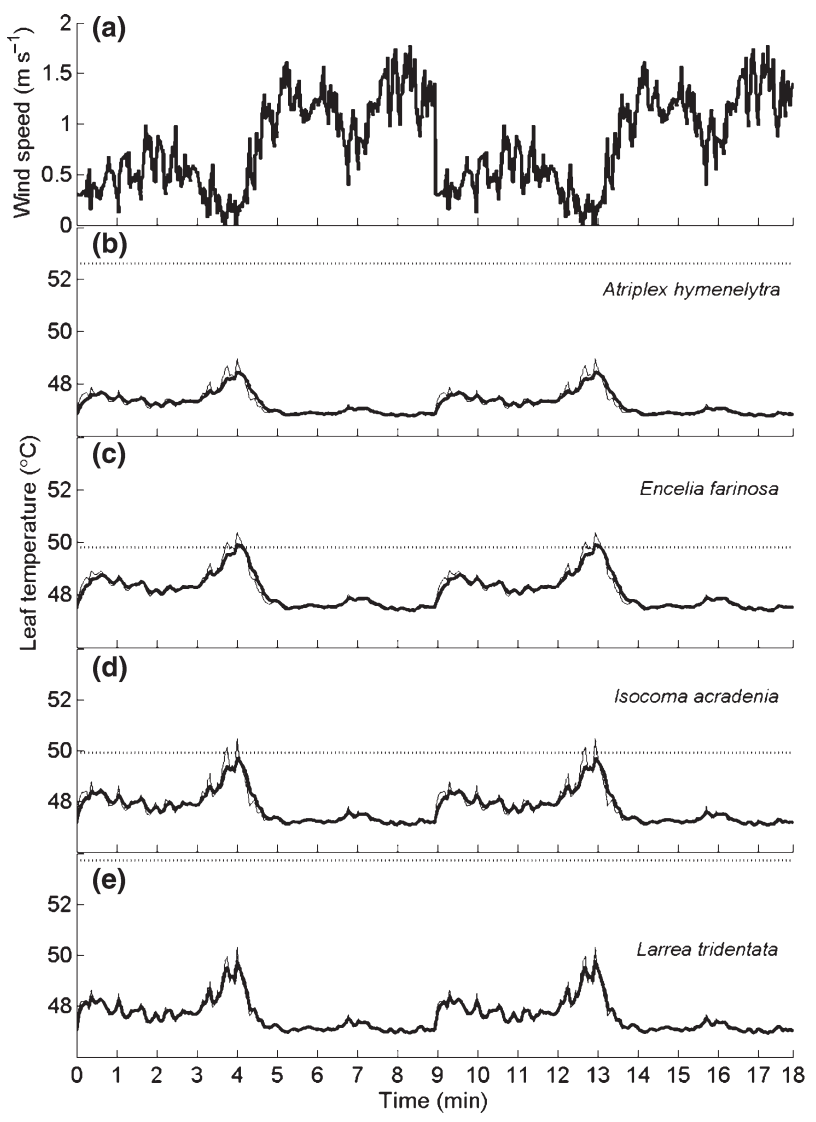

Fig. 3 Leaf temperature responses of modelled Atriplex hymenelytra, Encelia farinosa, Isocoma acradenia and Larrea tridentata (b-e) to modelled wind speed fluctuations (a). The wind speed regime was digitized from the measured wind speed of Vogel (2005) and run for two cycles. For each leaf temperature response curve, the thick line represents the leaf of normal thickness for that species and the thin line represents a hypothetical thin leaf (thickness, $0.2 \mathrm{~mm}$ ). The ambient temperature was set to $46^{\circ} \mathrm{C}$, representing the average maximum temperature for the Mojave Desert in July. In each thickness comparison, all other leaf and environmental properties were as described in Tables 1,2. The dashed lines represent the damage ( $\left.T_{\text {S2O }}\right)$ threshold for each species (Knight \& Ackerly, 2002). whereas the temperature of the thick (normal) leaf never exceeded this threshold (Fig. 3).

Although more absorptive $(0.78$ and 0.85$)$ than the above two reflective species, the leaves of $I$. acradenia and $L$. tridentata were smaller, resulting in similar average temperatures: 47.9 and $48.1^{\circ} \mathrm{C}$ (Fig. 3). For both of these species, the combination of small size and high absorptance resulted in slightly greater amplitudes of temperature response to a wind lull. Nevertheless, the damping effect of increased thickness for these more absorptive species was also greater than for the reflective species (as predicted by Fig. 2). The modelled I. acradenia leaf did not reach its thermal damage threshold when the wind speed dropped (Time 3-4, Fig. 3), whereas its thin counterpart exceeded it twice during the same wind cycle. Under these same conditions, both the thick and thin modelled L. tridentata leaves avoided damaging temperatures completely, mainly because of the exceptionally high thermal damage threshold for this species: $53.7^{\circ} \mathrm{C}$.

\section{Discussion}

Under high ambient temperature, a momentary lull in air movement of only a few seconds can lead to a critically high leaf temperature if the period of the lull is longer than the time constant of the leaf. The high thermal mass of very thick leaves reduces the likelihood of rapid fluctuations to extreme temperature spikes (Ball et al., 1988). The present study addressed whether a minor change in thickness could be sufficient to reduce the incidence of thermal damage. Our model suggests that even modestly thick leaves can avoid thermal damage relative to leaves only fractions of a millimetre thinner (Fig. 3). We also found that such an increase in thickness reduced peak leaf temperatures more substantially than could be obtained by a realistic increase in water content for a given thickness (Fig. 2). Further, the damping benefit of increased thickness was of the same order of magnitude as the relative damping effect of a biologically reasonable increase in transpiration, decrease in absorptance or reduction in leaf size (Fig. 2).

Given the potential for transpirational cooling to substantially reduce leaf temperature (Gates, 1968), one might expect that increases of under a millimetre in thickness would be unlikely to effectively buffer against temperature excursions in transpiring leaves. Indeed, we found that a modest transpiration rate, typical for mature L. tridentata plants in favourable conditions, would have an overall temperature damping effect of up to $1^{\circ} \mathrm{C}$ greater than the effect of increasing thickness (Fig. 2a). Yet, the potential additive effect of more than one thermal regulatory property should be considered. Our model showed that, even for leaves transpiring at $5 \mathrm{mmol} \mathrm{m}^{-2} \mathrm{~s}^{-1}$, increasing the leaf thickness from 0.2 to $1.0 \mathrm{~mm}$ would have the effect of further damping the peak temperatures by at least $0.5^{\circ} \mathrm{C}$ (Fig. 2b). For nontranspiring leaves, this damping effect of thickness was doubled. $\mathrm{A} 1^{\circ} \mathrm{C}$ reduction in peak leaf temperature during a momentary wind lull could be critically important when high temperature extremes during summer drought conditions lead to stomatal closure.

Like transpiration, it was expected that high reflectance would have a strong influence in maintaining low leaf temperature. 
Thus, it was not surprising that a minor increase in thickness provided a negligible reduction in the peak temperature of modelled leaves that were highly reflective (absorptance < 0.3 ; Fig. $2 \mathrm{~d}$ ). However, for a leaf with an absorptance above 0.7 , an increase in thickness by $0.8 \mathrm{~mm}$ reduced the peak temperature by $>1^{\circ} \mathrm{C}$. Low absorptance of visible wavelengths limits carbon gain (Ehleringer et al., 1976) and desert species with leaf absorptances exceeding 0.8 are not uncommon (Sinclair \& Thomas, 1970). For species that hold their leaves for several seasons, high absorptance would mean a greater potential for carbon gain during months when transpiration could be sustained. Those same leaves during the height of summer, when latent heat loss would be negligible, would need other means of reducing peak temperatures. Our model showed that, for an absorptive species with a modest thermal damage threshold, such as I. acradenia, a greater thickness could mean the difference between repeated damage and avoiding it altogether (Fig. 3). Moreover, even for species with more reflective leaves, such as E. farinosa, increased thickness can still reduce the incidence of thermal damage when the damage threshold is low.

One factor that can influence the temperature of leaves, which was not adjusted for in our model, is their angle of display. Steep leaf angles can reduce incident radiation during the hottest time of day in desert plants (Mooney et al., 1977; Neufeld et al., 1988). In our model, leaves were assumed to be horizontal and we acknowledge that this is unrealistic for some species. Had our modelled leaves been angled, the incident heat load could have been reduced, which may have buffered temperature fluctuations in a similar way to low absorptance. For moderate to large leaf sizes, steeper leaf angles can also increase heat transfer via convective cooling (Vogel, 1970; Schuepp, 1973; Dixon \& Grace, 1983). Even so, the greatest temperature reduction by increased convection obtained through varying leaf angle is < 3\% (Vogel, 1970) and, for small leaves, the effect is thought to be negligible (Parkhurst et al., 1968; Thom, 1968).

The extent to which the influence of high absorptance can be moderated by reduced leaf size was illustrated by our model. The small size of $L$. tridentata leaves helped to counteract the temperature-increasing effects of high absorptance, whereas the slightly larger leaves of I. acradenia had slightly lower absorptance and showed a very similar average temperature. What had not been anticipated was the weakening damping effect of small size as leaf thickness increased (Fig. 2e). This effect was a result of the increasing importance of thermal mass (thickness) relative to the boundary layer (size) in governing the leaf time constant (Eqns 9, 10). Accordingly, the damping effect of increased thickness was greater in larger leaves, for example, up to $2.0^{\circ} \mathrm{C}$ for leaves of $40 \mathrm{~mm}$ across (Fig. 2f). Although leaves of this diameter do not represent an average in many desert environments (5-10 $\mathrm{mm}$ wide in most Californian desert species; Gibson, 1998), larger leaves nevertheless exist. For example, the 40 -mm-wide $E$. farinosa leaves in this study were larger than many desert leaves by an order of magnitude and, under our simulation, would have been damaged had they been thin (Fig. 3). For such large-leaved desert species, increased thickness would be a distinct advantage in damping peak temperatures during a wind lull on a hot summer's day.
Another outcome highlighted by the model was the relatively minor damping effect obtained by altering leaf water content. Intuitively, the leaves of desert succulents, which can average water contents of 0.85 (e.g. von Willert et al., 1992), will have a greater ability to damp rapid temperature fluctuations than much drier leaves of comparable thickness. However, the effect of increasing leaf water content within a biologically reasonable range (a very dry leaf would be 0.3 ; water content cannot exceed 1.0) was of the same order of magnitude as increasing leaf thickness within our conservative range of thicknesses $(0.2-1.0 \mathrm{~mm})$. This result is logical in light of the magnitude of these changes. Within an expected natural range, leaf water content can vary by only two- to three-fold, but leaf thickness can easily increase fivefold. Although water has a three- to four-fold greater specific heat capacity than dry matter (Monteith \& Unsworth, 1990; Simpson \& TenWolde, 1999), the two are of the same order of magnitude. Thus, varying the relative dry density or water content will achieve a small difference in damping, provided that leaves do not contain an unusually large volumetric fraction of air space (see Notes S3). Put simply, thick leaves will gain a temperature damping benefit as long as their greater thickness is achieved through increasing dry mass, water content or combinations thereof. This means that not only thick succulent leaves, but also thick leaves that are dense, tough and/or with high LMA are potentially less likely to incur thermal damage.

Thermal 'damage' is difficult to define because it depends not only on the temperature reached, but also on the severity, duration and number of times a leaf exceeds its thermal damage threshold. The $T_{\mathrm{S} 20}$ threshold is an accepted indicator of the onset of damage to the photosynthetic apparatus (Smillie \& Nott, 1979; Knight \& Ackerly, 2002). Yet, this threshold may undoubtedly be exceeded more than once before severe or irreversible damage occurs. In our model, the normal (thick) leaves of two species, E. farinosa and I. acradenia, did not exceed their thermal damage threshold when air movement dropped, whereas the hypothetical thin leaves exceeded these thresholds twice during the same wind lull. Thus, the severity (the height of the peak over the damage threshold), frequency (the number of times exceeding the threshold) and total duration (the length of time exceeding the threshold during a given excursion) of damage were greater for the modelled thin leaves of these species. The speed of recovery from damage to the photosynthetic machinery varies from minutes to hours (Haldimann \& Feller, 2004) to days, unless recovery does not occur (Karim et al., 1999). The relative and combined effects of severity, frequency and duration of heat stress on damage recovery are unknown. However, one factor known to impede recovery from damage is leaf age (Karim et al., 1999). It is therefore reasonable to surmise that reduced severity, frequency and duration of exposure to damaging temperatures would be particularly important for species with long-lived leaves.

The role of increased thickness in reducing thermal damage supports the well-known association between high-LMA (often thick) leaves and long leaf lifespan in nutrient-poor environments. For example, Australian desert plants have relatively thick, long-lived leaves (Wright \& Westoby, 2002) and grow in soils 
that are uncommonly low in nutrients (Morton et. al., 2011). In such conditions, prolonging the leaf lifespan could be achieved through the production of leaves that are not only structurally tough and herbivore resistant, but also resistant to thermal damage. In nutrient-poor environments, the production of physiological protective compounds, such as isoprenes and heat shock proteins, represents a relatively high carbon and/or nitrogen cost (Vierling, 1991; Knight \& Ackerly, 2001; Sharkey et al., 2008). Where the viability of physiological thermal protection is reduced, built-in structural alternatives to avoid repeated heat stress events would promote the survival of leaves through several years. We suggest that an additional way of extending the lifespan of a leaf is through the mitigation of repeated thermal damage via increasing thickness.

\section{Acknowledgements}

The authors gratefully acknowledge the ARC-NZ Network for Vegetation Function in supporting this work. S. Sevanto was supported by the Office of Science (BER), Department of Energy, grant no. DE-FG02-07ER64393. We are grateful to Graham Farquhar for thoughtful comments on an earlier version of the model and to three anonymous reviewers for comments on earlier versions of the manuscript. We thank the Sweeney Granite Mountains Desert Research Centre for access to their facilities.

\section{References}

Aerts R, Chapin FS. 2000. The mineral nutrition of wild plants revisited: a reevaluation of processes and patterns. Advances in Ecological Research 30: 1-67.

Ball MC, Cowan IR, Farquhar GD. 1988. Maintenance of leaf temperature and the optimization of carbon gain in relation to water loss in a tropical mangrove forest. Australian Journal of Plant Physiology 15: 263-276.

Barradas VL, Jones HG, Clark JA. 1994. Stomatal responses to changing irradiance in Phaseolus vulgaris L. Journal of Experimental Botany 45: 931-936.

Bird RB, Stewart WE, Lightfoot EN. 2002. Transport phenomena. New York, NY, USA: John Wiley and Sons.

Campbell GS, Norman JM. 1998. An introduction to environmental biophysics. New York, NY, USA: Springer-Verlag.

Dixon M, Grace J. 1983. Natural convection from leaves at realistic Grashof numbers. Plant, Cell \& Environment 6: 665-670.

Ehleringer J, Bjorkman O, Mooney HA. 1976. Leaf pubescence - effects on absorptance and photosynthesis in a desert shrub. Science 192: 376-377.

Ehleringer J, Mooney HA, Gulmon SL, Rundel PW. 1981. Parallel evolution of leaf pubescence in Encelia in coastal deserts of North America and South America. Oecologia 49: 38-41.

Gaines SD, Denny MW. 1993. The largest, smallest, highest, lowest, longest, and shortest: extremes in ecology. Ecology 74: 1677-1692.

Gates DM. 1962. Energy exchange in the biosphere. New York, NY, USA: Harper and Row.

Gates DM. 1968. Transpiration and leaf temperature. Annual Review of Plant Physiology 19: 211-238.

Gibson AC. 1998. Photosynthetic organs of desert plants. BioScience 48: 911-920.

Grace J. 1977. Plant response to wind. London, UK: Academic Press.

Grace J, Fasehun FE, Dixon M. 1980. Boundary layer conductance of the leaves of some tropical timber trees. Plant, Cell \& Environment 3: 443-450.

Grace J, Wilson J. 1976. The boundary layer over a Populus leaf. Journal of Experimental Botany 27: 231-241.

Groom PK, Lamont BB, Leighton S, Leighton P, Burrows C. 2004. Heat damage in sclerophylls is influenced by their leaf properties and plant environment. Ecoscience 11: 94-101.
Haldimann P, Feller U. 2004. Inhibition of photosynthesis by high temperature in oak (Quercus pubescens L.) leaves grown under natural conditions closely correlates with a reversible heat-dependent reduction of the activation state of ribulose-1,5-bisphosphate carboxylase/oxygenase. Plant, Cell \& Environment 27: 1169-1183.

Hamerlynck EP, Huxman TE, Loik ME, Smith SD. 2000. Effects of extreme high temperature, drought and elevated $\mathrm{CO}_{2}$ on photosynthesis of the Mojave Desert evergreen shrub, Larrea tridentata. Plant Ecology 148: 183-193.

James SA, Bell DT. 1995. Morphology and anatomy of leaves of Eucalyptus camaldulensis clones - variation between geographically separated locations. Australian Journal of Botany 43: 415-433.

Jayalakshmy MS, Philip J. 2010. Thermophysical properties of plant leaves and their influence on the environment temperature. International Journal of Thermophysics 31: 2295-2304.

Karim MA, Fracheboud Y, Stamp P. 1999. Photosynthetic activity of developing leaves of Zea mays is less affected by heat stress than that of developed leaves. Physiologia Plantarum 105: 685-693.

Knight CA, Ackerly DD. 2001. Correlated evolution of chloroplast heat shock protein expression in closely related plant species. American Journal of Botany 88: 411-418.

Knight CA, Ackerly DD. 2002. An ecological and evolutionary analysis of photosynthetic thermotolerance using the temperature-dependent increase in fluorescence. Oecologia 130: 505-514.

Leakey ADB, Scholes JD, Press MC. 2005. Physiological and ecological significance of sunflecks for dipterocarp seedlings. Journal of Experimental Botany 56: 469-482.

Liang KM, Lin ZF, Ren H, Liu N, Zhang QM, Wang J, Wang ZF, Guan LL. 2010. Characteristics of sun- and shade-adapted populations of an endangered plant Primulina tabacum Hance. Photosynthetica 48: 494-506.

Medeiros JS, Pockman WT. 2010. Carbon gain and hydraulic limits on water use differ between size classes of Larrea tridentata. Journal of Arid Environments 74: 1121-1129.

Monteith JL, Unsworth MH. 1990. Principles of environmental physics. London, UK: Edward Arnold.

Mooney HA, Ehleringer J, Bjorkman O. 1977. The energy balance of leaves of evergreen desert shrub Atriplex hymenelytra. Oecologia 29: 301-310.

Morton SR, Smith DMS, Dickman CR, Dunkerley DL, Friedel MH, McAllister RRJ, Reid JRW, Roshier DA, Smith MA, Walsh FJ et al. 2011. A fresh framework for the ecology of arid Australia. Journal of Arid Environments 75: 313-329.

Neufeld HS, Meinzer FC, Wisdom CS, Sharifi MR, Rundel PW, Neufeld MS, Goldring Y, Cunningham GL. 1988. Canopy architecture of Larrea tridentata (DC) COV, a desert shrub: foliage orientation and direct beam radiation interception. Oecologia 75: 54-60.

Niinemets U. 2001. Global-scale climatic controls of leaf dry mass per area, density, and thickness in trees and shrubs. Ecology 82: 453-469.

Nobel PS. 1988. Environmental biology of Agaves and Cacti. Cambridge, UK: Cambridge University Press.

Nobel PS. 2005. Physicochemical and environmental plant physiology. San Diego, CA, USA: Elsevier Academic Press.

Panditharathna P, Singhakumara BMP, Griscom HP, Ashton MS. 2008. Change in leaf structure in relation to crown position and size class for tree species within a Sri Lankan tropical rain forest. Botany-Botanique 86: 633-640.

Parkhurst DF, Duncan PR, Gates DM, Kreith F. 1968. Wind-tunnel modelling of convection of heat between air and broad leaves of plants. Agricultural Meteorology 5: 33-47.

Reich PB, Walters MB, Ellsworth DS. 1997. From tropics to tundra: global convergence in plant functioning. Proceedings of the National Academy of Sciences, USA 94: 13730-13734.

Roden JS, Pearcy RW. 1993. The effect of flutter on the temperature of poplar leaves and its implication for carbon gain. Plant, Cell \& Environment 16: 571-577.

Roderick ML, Berry SL, Noble IR. 2000. A framework for understanding the relationship between environment and vegetation based on the surface area to volume ratio of leaves. Functional Ecology 14: 423-437. 
Schuepp PH. 1972. Studies of forced-convection heat and mass transfer of fluttering realistic leaf models. Boundary-Layer Meteorology 2: 263-274.

Schuepp PH. 1973. Model experiments on free-convection of leaves and plant elements. Boundary-Layer Meteorology 3: 454-467.

Schuepp PH. 1993. Tansley Review No. 59. Leaf boundary layers. New Phytologist 125: 477-507.

Sharkey TD. 2005. Effects of moderate heat stress on photosynthesis: importance of thylakoid reactions, rubisco deactivation, reactive oxygen species, and thermotolerance provided by isoprene. Plant, Cell \& Environment 28: 269-277.

Sharkey TD, Wiberley AE, Donohue AR. 2008. Isoprene emission from plants: why and how. Annals of Botany 101: 5-18.

Simpson W, TenWolde A. 1999. Physical properties and moisture relations of wood. Wood handbook - wood as an engineering material. Madison, WI, USA: Forest Products Laboratory, USDA Forest Services, 1-25.

Sinclair R, Thomas DA. 1970. Optical properties of leaves of some species in arid South Australia. Australian Journal of Botany 18: 261-273.

Smillie RM, Nott R. 1979. Heat injury in leaves of alpine, temperate and tropical plants. Australian Journal of Plant Physiology 6: 135-141.

Su H, Li YG, Lan ZJ, Xu H, Liu W, Wang BX, Biswas DK, Jiang GM. 2009. Leaf-level plasticity of Salix gordejevii in fixed dunes compared with lowlands in Hunshandake Sandland, North China. Journal of Plant Research 122: 611-622.

Terashima I, Miyazawa SI, Hanba YT. 2001. Why are sun leaves thicker than shade leaves? Consideration based on analyses of $\mathrm{CO}_{2}$ diffusion in the leaf Journal of Plant Research 114: 93-105.

Thom AS. 1968. Exchange of momentum mass and heat between an artificial leaf and airflow in a wind tunnel. Quarterly Journal of the Royal Meteorological Society 94: 44-55.

The Weather Channel. URL http://www.weather.com/ [accessed on 10 September 2011].

Venditti C, Meade A, Pagel M. 2010. Phylogenies reveal new interpretation of speciation and the Red Queen. Nature 463: 349-352.

Vendramini F, Diaz S, Gurvich DE, Wilson PJ, Thompson K, Hodgson JG. 2002. Leaf traits as indicators of resource-use strategy in floras with succulent species. New Phytologist 154: 147-157.

Vierling E. 1991. The roles of heat-shock proteins in plants. Annual Review of Plant Physiology and Plant Molecular Biology 42: 579-620.

Vogel S. 1970. Convective cooling at low airspeeds and the shapes of broad leaves. Journal of Experimental Botany 21: 91-101.

Vogel S. 2005. Living in a physical world. V. Maintaining temperature. Journal of Biosciences 30: 581-590.
Vogel S. 2009. Leaves in the lowest and highest winds: temperature, force and shape. New Phytologist 183: 13-26.

Voronin PY, Ivanova LA, Ronzhina DA, Ivanov LA, Anenkhonov OA, Black CC, Gunin PD, P'Yankov VI. 2003. Structural and functional changes in the leaves of plants from steppe communities as affected by aridization of the Eurasian climate. Russian Journal of Plant Physiology 50: 604-611.

Westoby M, Falster DS, Moles AT, Vesk PA, Wright IJ. 2002. Plant ecological strategies: some leading dimensions of variation between species. Annual Review of Ecology and Systematics 33: 125-159.

von Willert DJ, Eller BM, Werger MJA, Brinckmann E, Ihlenfeldt I-H. 1992. Life strategies of succulents in deserts: with special reference to the Namib Desert. Cambridge, UK: Cambridge University Press.

Wright IJ, Westoby M. 2002. Leaves at low versus high rainfall: coordination of structure, lifespan and physiology. New Phytologist 155: 403-416.

Wright IJ, Westoby M, Reich PB. 2002. Convergence towards higher leaf mass per area in dry and nutrient-poor habitats has different consequences for leaf life span. Journal of Ecology 90: 534-543.

\section{Supporting Information}

Additional supporting information may be found in the online version of this article.

Fig. S1 The effect of increasing the temperature difference between leaf and ambient air on the transpiration rate at two different ambient temperatures $\left(46\right.$ and $\left.25^{\circ} \mathrm{C}\right)$.

Notes S1 Model tests.

Notes S2 Effects of dynamic transpiration.

Notes S3 Air fraction extrapolation.

Please note: Wiley-Blackwell are not responsible for the content or functionality of any supporting information supplied by the authors. Any queries (other than missing material) should be directed to the New Phytologist Central Office. 